JIOM Nepal. Volume 41 Number 3. December 2019, page 24-29.

\title{
Awareness Regarding Hypertension among Adults in a Community of Bhaktapur, Nepal
}

\author{
Sanju Pokhrel', Tulza KC ${ }^{2}$ \\ Department of Adult Nursing, Maharajgunj Nursing Campus, Institute of Medicine, Maharajgunj, Kathmandu \\ Corresponding author: \\ Tulza KC \\ Department of Adult Nursing, Maharajgunj Nursing Campus, Institute of Medicine, Maharajgunj, Kathmandu \\ Email:tulza.kc@hotmail.com
}

Submitted : November 3, 2019

Accepted : December 8, 2019

\begin{abstract}
Introduction

Hypertension is a common global health problem with significant morbidity and mortality. Various preventive life style practices play significant role in controlling it. The objective of this study was to identify awareness regarding hypertension among the adult people in a community of Bhaktapur, Nepal.

\section{Methods}

A descriptive cross-sectional study was conducted among 138 adults aged 20-59 residing in Bhaktapur, selected through non probability purposive sampling technique. The data was collected by face to face interview method through semi structured questionnaire. Data was analyzed by using descriptive and inferential statistics.
\end{abstract}

\section{Results}

The study showed that $58.7 \%$ of adults had adequate awareness regarding hypertension. About $35.5 \%$ knew the range of value of high blood pressure and nearly half (47.8\%) answered heart as the organ primarily related to hypertension. Stress was identified as a risk for hypertension by $96.4 \%, 92 \%$ specified headache as main symptom and only $31.9 \%$ knew about the asymptomatic nature of hypertension. Nearly 90\% were aware that management of hypertension includes all: medicine, diet and exercise. Almost 99\% of the respondents mentioned about restricting alcohol for BP control and $93.2 \%$ mentioned heart attack as the complication of hypertension.

\section{Conclusion}

The study concluded that only half of adults have adequate awareness regarding hypertension. It also showed that there is statistically significant association of awareness level with age, religion, educational status, occupation, economic status, family history and diagnosis of hypertension. Thus, it could be recommended that health personnel should provide education and information covering all aspects of hypertension to adults residing in community.

Keywords: Adult people, awareness, hypertension

\section{INTRODUCTION}

$\mathrm{H}$ ypertension (HTN) is the most common lifestyle-related disease ${ }^{1}$ and has often been described as a 'silent killer' because it increases the risk of heart attack, stroke, and other medical problems without any early warning symptoms. ${ }^{2,3}$

Globally, approximately 4 in 10 adults older than 25 years have hypertension. ${ }^{4}$ In the South-East Asia
Region, $36 \%$ of adults have HTN.5 In Nepal, $17 \%$ of women and $23 \%$ of men aged 15 and older have hypertension. ${ }^{6}$ Of cardiovascular diseases (CVDs), complications of HTN account for 9.4 million deaths worldwide every year comprising at least $45 \%$ of deaths due to ischemic heart disease and $51 \%$ due to stroke. ${ }^{7}$

Increasing public awareness is a key to early detection of HTN. ${ }^{3}$ In several countries in South 
East Asia, awareness level of HTN is less than $50 \%$. Of those aware that they have hypertension, about half are on treatment, following the global rule of halves in HTN. ${ }^{8}$ Urbanization is increasing the risk for non-communicable diseases in Nepal because of the lifestyle changes that it invariably causes. A study comparing the prevalence of HTN in the same community in 1981 and 2006 reported a threefold increase in prevalence $(31 \%)$ and concluded that compliance with medication and knowledge of behavioral changes remain low among diagnosed, highlighting the inadequacy of the current health-care system in preventing and controlling hypertension. ${ }^{9}$ Similarly, a population based study done in Nepal showed 38\% awareness among rural and urban population only in terms of having hypertensive status as told by the clinicians or other health professionals that they have high blood pressure. ${ }^{10}$ Hence, the aim of the study was to find out the awareness regarding basic concepts of hypertension among adult people in a community of Bhaktapur.

\section{METHODS}

A descriptive cross sectional research design was used for the study. The study was conducted in the community of Bode, Ward no. 9 of Madhyapur Thimi Submunicipality, Bhaktapur district, Nepal. The study area was purposively selected since previous study findings of rural Bhaktapur ${ }^{11}$ and rural Kathmandu ${ }^{12}$ had shown a sharp rise in HTN prevalence largely because of changing lifestyle and socio-economic transition. The study population was the adult people of age group 2059 years residing in Bode. A total of 138 adults (one adult from each family) who agreed to take part in the study and were present in the community in the data collection period were selected using non-probability purposive sampling method.

A semi-structured questionnaire was developed by researchers consisting of two parts: sociodemographic characteristics consisting 10 items and 28 items related to awareness on hypertension. Questionnaire was developed in Nepali language. Data was collected after obtaining ethical approval from Nepal Health Research Council and Ward Office of the selected community. All the respondents were explained the objectives and requested for voluntary participation, and an informed written consent was obtained before collecting data through interview method. Data collection was done from 17 July to 10 August 2018. Data was analyzed with descriptive statistics and inferential statistics at 0.05 level of significance.
One third of respondents (33.3\%) were of age group of 30-40 years and more than half (52.9\%) were male. Around half of the respondents were Janajati (48.6\%) followed by Brahmin/ Chhetri $(43.5 \%)$ and $89.1 \%$ were Hindu. Majority $(70.3 \%)$ lived in nuclear family and more than half $(52.9 \%)$ were engaged in business. Most of them $(87.7 \%)$ were literate among which about half of them (51.2\%) had completed higher secondary education and above. Similarly, majorities (81.9\%) were married and more than half of respondents $(55.8 \%)$ were having economic status sufficient for living up to 6-12 months. Similarly, 55.8\% had family history of hypertension among which majority of respondents' parents (63.7\%) were having hypertension. Moreover, only $10.9 \%$ had been diagnosed with hypertension and $60 \%$ of diagnosed were having duration of diagnosis less than 5 years.

Among total, 58\% respondents gave the correct answer of normal blood pressure in adult, only $35.5 \%$ gave correct answer regarding high blood

Table 1. Respondents' awareness on hypertension: basic concepts, risk factors and symptoms $(n=138)$

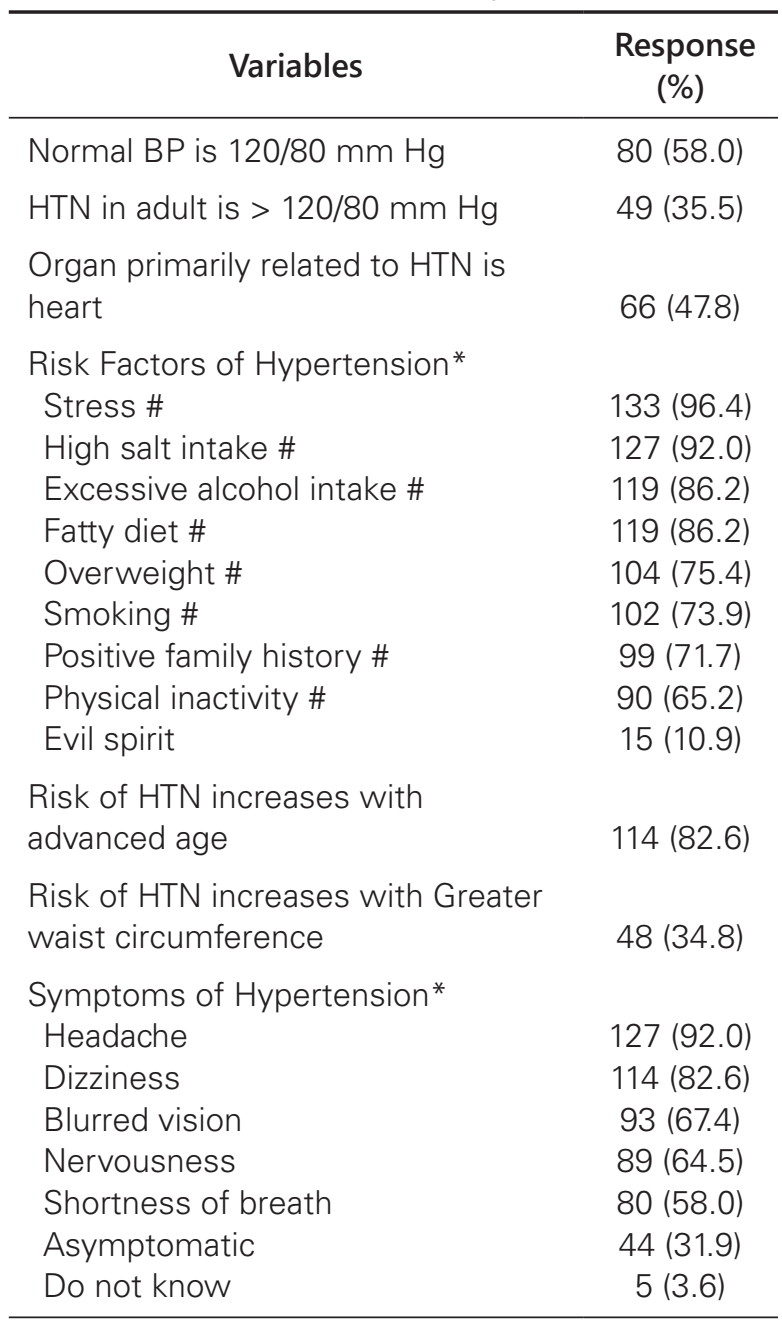

*Multiple response, \# Correct response 
Table 2. Respondents' awareness on hypertension: management, control and complications $(n=138)$

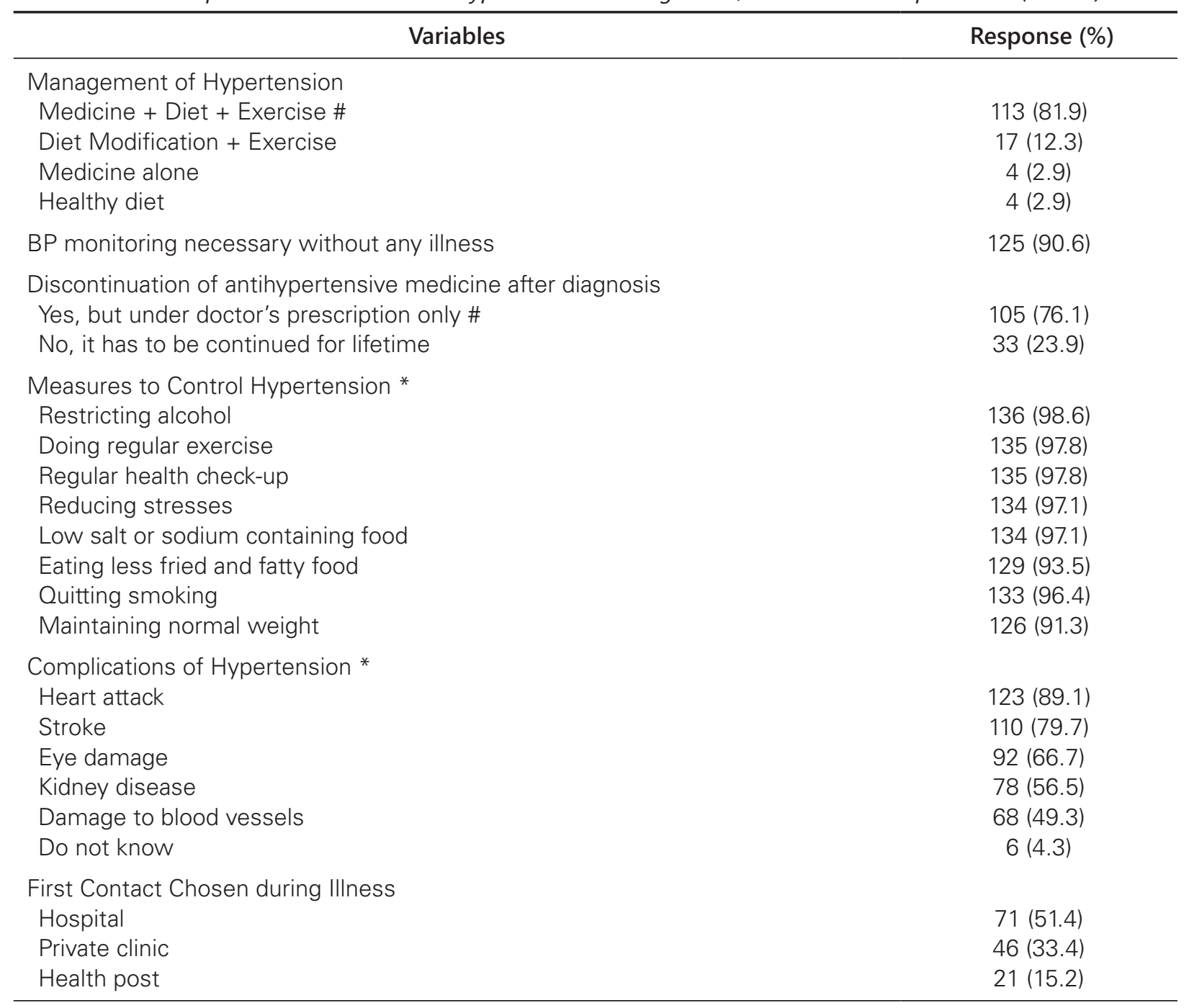

*Multiple response, \# Correct response

pressure and $47.8 \%$ answered heart as the organ primarily related to HTN. Stress was identified as a risk factor of HTN by $96.4 \%$ while $10.9 \%$ believed that evil spirit may also be responsible. $82.6 \%$ replied that risk increases with advanced age and only $34.8 \%$ had idea about the risk of HTN with greater waist circumference. Ninety two percent specified headache as main symptom (Table 1).

Table 2 shows that $81.9 \%$ of respondents were aware that management of HTN includes all medicine, diet and exercise and 90.6\%

Table 3. Respondents' level of awareness on hypertension $(n=138)$

\begin{tabular}{lc}
\hline \multicolumn{1}{c}{ Level of awareness } & Frequency (\%) \\
\hline $\begin{array}{l}\text { Inadequate awareness } \\
(<\text { mean score) }\end{array}$ & 57 (41.3) \\
$\begin{array}{l}\text { Adequate awareness } \\
(\geq \text { mean score) }\end{array}$ & 81 (58.7) \\
\hline Total score $=40$, Mean score $=28.68$
\end{tabular}
without any illness. Similarly, 76.1\% replied that antihypertensive medicine can be stopped only under doctor's prescription. Regarding measures to control hypertension, $98.6 \%$ mentioned alcohol restriction. Most of them (93.2\%) mentioned heart attack as the complication of hypertension and $97.7 \%$ were aware that complications of HTN can be preventable and $51.4 \%$ specified hospital as their first contact during illness. Similarly, table 3 illustrates that more than half of the respondents (58.7\%) have had adequate level of awareness and $41.3 \%$ have inadequate level of awareness regarding hypertension. Table 4 illustrates that there was significant association between level of awareness with age $(p=0.042)$, religion (0.035), occupation (0.011), educational status (0.036), economic status, family history (0.007) and diagnosis of hypertension (0.020) However, there is no association between level of awareness with sex (0.958) and ethnicity (0.127) of respondents. 
Table 4. Association between Respondents' Level of Awareness and Selected Variables $(n=138)$

\begin{tabular}{|c|c|c|c|c|}
\hline Variables & $\begin{array}{c}\text { Inadequate awareness } \\
\text { No. (\%) }\end{array}$ & $\begin{array}{c}\text { Adequate awareness } \\
\text { No. (\%) }\end{array}$ & $x^{2}$ & $\mathrm{p}$-value \\
\hline $\begin{array}{l}\text { Age (in completed years) } \\
20-39 \\
40-59\end{array}$ & $\begin{array}{l}42(47.7) \\
15(30.0)\end{array}$ & $\begin{array}{l}46(52.3) \\
35(70.0)\end{array}$ & 4.133 & 0.042 \\
\hline $\begin{array}{l}\text { Sex } \\
\text { Male } \\
\text { Female }\end{array}$ & $\begin{array}{l}30(41.1) \\
27(41.5)\end{array}$ & $\begin{array}{l}43(58.9) \\
38(58.5)\end{array}$ & 0.003 & 0.958 \\
\hline $\begin{array}{l}\text { Ethnicity } \\
\text { Brahmin/ Chhetri } \\
\text { Janajati } \\
\text { Othersa }\end{array}$ & $\begin{array}{c}19(31.7) \\
33(49.3) \\
5(45.5)\end{array}$ & $\begin{array}{l}41(68.3) \\
34(50.7) \\
6(54.5)\end{array}$ & 4.123 & 0.127 \\
\hline $\begin{array}{l}\text { Religion } \\
\text { Hinduism } \\
\text { Other than Hindu }\end{array}$ & $\begin{array}{l}47(38.2) \\
10(66.7)\end{array}$ & $\begin{array}{l}76(61.8) \\
5(33.3)\end{array}$ & 4.465 & 0.035 \\
\hline $\begin{array}{l}\text { Occupation } \\
\text { Agriculture \& Household } \\
\text { Service } \\
\text { Business } \\
\text { Labour \& Othersb }\end{array}$ & $\begin{array}{c}5(22.7) \\
6(28.6) \\
31(42.5) \\
15(68.2)\end{array}$ & $\begin{array}{c}17(77.3) \\
15(71.4) \\
42(57.5) \\
7(31.8)\end{array}$ & 11.132 & 0.011 \\
\hline $\begin{array}{l}\text { Educational Status } \\
\text { Illiterate } \\
\text { Literate }\end{array}$ & $\begin{array}{l}11(64.7) \\
46(38.0)\end{array}$ & $\begin{array}{c}6(35.3) \\
75(62.0)\end{array}$ & 4.380 & 0.036 \\
\hline $\begin{array}{l}\text { Economic Status } \\
\text { Sufficient for } 6 \text { months } \\
\text { Sufficient for } 6-12 \text { months } \\
\text { Sufficient for } 1 \text { year\& extra } \\
\text { saving }\end{array}$ & $\begin{array}{l}21(56.8) \\
31(40.3) \\
5(20.8)\end{array}$ & $\begin{array}{l}16(43.2) \\
46(59.7) \\
19(79.2)\end{array}$ & 7.827 & 0.020 \\
\hline $\begin{array}{l}\text { Family History } \\
\text { Yes } \\
\text { No }\end{array}$ & $\begin{array}{l}24(31.2) \\
33(54.1)\end{array}$ & $\begin{array}{l}53(68.8) \\
28(45.9)\end{array}$ & 7.381 & 0.007 \\
\hline $\begin{array}{l}\text { Diagnosed having } \\
\text { Hypertension } \\
\text { Yes } \\
\text { No }\end{array}$ & $\begin{array}{c}2(13.3) \\
55(44.7)\end{array}$ & $\begin{array}{l}13(86.7) \\
68(55.3)\end{array}$ & 5.431 & 0.020 \\
\hline
\end{tabular}

\section{DISCUSSION}

More than half (58\%) of respondents could correctly state normal blood pressure measurement which is consistent with the study done in Ghana where $50 \%$ had good knowledge on normal blood pressure values. ${ }^{13}$ With regard to risk factors of hypertension, almost all respondents (96.4\%) in this study replied that stress is a risk factor, $75.4 \%$ mentioned about overweight and $73.9 \%$ mentioned about smoking. Similar findings were noted in the study done in Nigerian adults where the most common cause mentioned was psychosocial stress $(90 \%)$, obesity by $65 \%$ and smoking by $64 \% .{ }^{14}$ Also, 92\% respondents of current study mentioned that high salt intake can lead to hypertension which is similar to study of Ghana where $91 \%$ agreed on excessive salt intake as a cause of high blood pressure. ${ }^{13}$ Similarly, majority $(82.6 \%)$ replied the advanced age as a risk factor and $71.7 \%$ believed that positive family history increases the risk of high blood pressure. Contrary to this finding, Pandey et al have highlighted that only $46.9 \%$ knew age as non-modifiable risk factor for heart disease followed by hereditary $(39.8 \%))^{13}$ However, in this study, $10.9 \%$ believed that evil spirit may also be responsible for hypertension which is contradictory to the study done in Nigerian where only $9.1 \%$ strongly disagreed for evil spirits causing hypertension. ${ }^{16}$ This might be due to difference in setting and population. 
Most of the respondents (92\%) specified headache as main symptom followed by dizziness (82.6\%) while $3.6 \%$ had no idea about the symptoms. A similar study done in Ghana showed that $88 \%$ specified headache, dizziness as the symptoms of high blood pressure and about 3\% did not know the symptoms. ${ }^{13}$ This finding is also supported by the study of Kavre, Nepal which concluded that majority of respondents were aware of a headache and dizziness as the symptoms of HTN. ${ }^{17}$ Moreover, present study showed that only $31.9 \%$ identified asymptomatic nature of hypertension. Similar finding was mentioned in a study done in Nigeria where $36.1 \%$ mentioned asymptomatic nature of hypertension. ${ }^{16}$

Majority of the adults (81.9\%) in this study were aware that management of hypertension includes all: medicine, diet and exercise and most of them (90.6\%) were aware that regular BP monitoring is necessary without any illness. This finding varies with the study done in Kavre, Nepal where only $58 \%$ believed that combination of healthy diet, medicines, and physical activity will help in management of HTN and only $46.7 \%$ knew that regular BP monitoring is necessary. ${ }^{17}$ This inconsistency may be due to the dissimilarity in lifestyle of respondents and difference in setting and population.

Present study showed that about $4.3 \%$ were not aware about complications of HTN which is similar to the study done in Nigeria where only $3.7 \%$ believed that hypertension leads no complications. ${ }^{14}$ Majority (89.1\%) of this study mentioned heart attack as the complication of HTN. $56.5 \%$ were aware about hypertension leading to kidney damage, $66.7 \%$ knew about eye damage and nearly all respondents (97.7\%) were aware that complications of hypertension can be preventable. Similar findings were noted by the study of Nepal where $57 \%$ were aware on kidney failure and $60.4 \%$ about eye damage as complications of HTN. ${ }^{17}$ Besides this, another study of Ghana also concluded the high knowledge $(90 \%)$ of respondents on blood pressure prevention. ${ }^{13}$

Regarding the measures to control hypertension, $97.8 \%$ recognized doing regular exercise, $96.4 \%$ replied quitting smoking, $98.6 \%$ mentioned restricting alcohol, 91.3\% answered maintaining normal weight, $97.1 \%$ mentioned low salt intake and $97.1 \%$ mentioned reducing stress. However, these study findings vary with the study of Ghana where only $40 \%$ recognized doing regular exercise, $12 \%$ mentioned maintaining normal weight, $15 \%$ mentioned limiting alcohol, 15\% mentioned stopping smoking, $8 \%$ of respondents had identified low salt intake and only $5 \%$ recognized reducing stress as the preventive measures of hypertension. ${ }^{13}$ The variation in the study findings might be due to difference in setting and lifestyle of respondents.

About half of the respondents $(51.4 \%)$ of this study specified hospital as their first contact during illness, followed by private clinics $(33.4 \%)$ while only $15.2 \%$ respondents specified health post as their first contact during illness. But dissimilar findings were noted in the study of Pokhara, Nepal, where the source of medical care was the primary health centre $(\mathrm{PHC}) /$ health post in $31.8 \%$ and hospital in $36.4 \%$ respondents. ${ }^{18}$ Regarding level of awareness, more than one third (41.3\%) of the respondents have had inadequate level of awareness on hypertension. Similar finding was reported by the study done in Turkey where frequency of having low level of knowledge about HTN was $31.3 \% .^{19}$

This study showed significant association on level of awareness with family history of hypertension $(p=0.007)$. Similar finding was reported by the study done in Nigeria and Pokhara, Nepal where the knowledge score was significantly higher among respondents whose family members were suffering from cardiovascular disease. ${ }^{14,18}$ Furthermore, findings of this study showed statistical significant association between level of awareness and economic status which is similar to the study carried out in Pokhara where the knowledge scores were significantly lower among respondents with low monthly family income.18 This study also showed significant association between level of awareness with age, religion, occupation, and educational status which is supported by the study done in Ranchi, India where age, educational status of the study subjects were found to be significantly associated with awareness on HTN. ${ }^{20}$ However, no significant association found between level of awareness with sex and ethnicity which is contradictory to the study done in Ranchi, ${ }^{20}$ where sex and ethnicity of the study subjects were found to be significantly associated with awareness on HTN. This variation might be due to the limited age group selection in the study and small sample size.

\section{CONCLUSION}

More than half of the adults have adequate level of awareness regarding hypertension. Likewise, adults' level of awareness tends to be associated with age, religion, occupation, educational status, economic status, family history and diagnosis of hypertension. However, the level of awareness among adults is not associated with sex and ethnicity. 


\section{ACKNOWLEDGEMENT}

Authors would like to express special thanks to the authorities of Ward Office, Bode, Bhaktapur and the participating adults of Bode, ward number 9, Bhaktapur for their co-operation, support and participation.

\section{CONFLICT OF INTEREST}

None declared.

\section{REFERENCES}

1. Shimamoto $K$, Ando $K$, Flujita T, Hasebe $N$, Higaki $J$, Horiuchi $M$, et al. The japanese society of hypertension guidelines for the management of hypertension. Hypertens Res. 2014; 37: 253-392.

2. Khoury SR, Ratchford EV. Hypertension. Vascular Medicine.2018; 23(3): 293-297.

3. Rao V, Daniel A. Application of the "Rule of Halves" for hypertension as an assessment tool in an urban slum at davangere. Natl J Community Med. $2014 ; 5(3): 333-6$.

4. Campbell RC, Lackland DT, Niebylski ML. High blood pressure: why prevention and control are urgent and important: a 2014 fact sheet from the World Hypertension League and the International Society of Hypertension. The Journal of Clinical Hypertension. 2014; 16(8): 551-3.

5. World Health Organization. Fact sheets on Noncommunicable diseases. 2018. Available from http://www.who.int/news-room/fact-sheets/ detail/noncommunicable-diseases.

6. Ministry of Health, New ERA, ICF. Nepal demographic and health survey 2016. Kathmandu, Nepal. 2017. Available from https://www. dhsprogram.com/pubs/pdf/fr336/fr336.pdf

7. World Health Organization. A global brief on hypertension. 2013. Available from http://www. who.int/cardiovascular_diseases/publications/ global_brief_hypertension/en/

8. Castillo R. Prevalence and management of hypertension in Southeast Asia. Journal of Hypertension. 2016.

9. Dhital SM, Karki A. Dealing with the burden of hypertension in Nepal: current status, challenges and health system issues. Regional Health Forum. 2013; 17(1): 44-52.

10. Mehata S, Shrestha N, Mehta R, Vaidya A, Rawale
LB, Bhattarai N. et al. Prevalence, awareness, treatment and control of hypertension in Nepal: data from nationally representative populationbased cross-sectional study. Journal of Hypertension. 2018; 36(8).

11. Vaidya A, Pathak, RP, Pandey, MR. Prevalence of hypertension in Nepalese community triples in 25 years: a repeat cross-sectional study in rural Kathmandu. Indian Heart J. 2012; 64(2): 128-131.

12. Vaidya A. Is Ethnicity an Important Determinant of High Blood Pressure in Nepalese Population? A Community-Based Cross-Sectional Study in Duwakot, Nepal. Kathmandu Univ Med J. 2012; 37(1):20-3

13. Kofi JO. Prevention and Management of Hypertension: A study on knowledge and attitudes of women of childbearing age. Bachelor's thesis: Central Ostrobothnia University of Applied Sciences, Kokkola, Finland. 2011 Available from https://www.theseus.fi/bitstream/ handle/10024/41325/Kofi_Janet\%20pdf.pdf

14. Oke DA, Bandele EO. Misconceptions of hypertension. Journal of the National Medical Association.2004; 96(9): 1221-1224.

15. Pandey $R$, Khadka I. Knowledge regarding preventive measures of heart disease among the adult population in Kathmandu. Health. 2012; 4(9): 601-606.

16. Azubuike SO, Kurmi R. Awareness, practices, and prevalence of hypertension among rural Nigerian women. Archives of Medicine \& Health Sciences. 2014; 2(1): 23- 28.

17. Kharel S, Mainalee M. Awareness of Hypertension Among Rural Kavreli Male Adults of Nepal. International Annals of Medicine. 2017; 1(3).

18. Shankar PR, Partha $P$, Shenoy $N$, Chandrasekhar TS, Dubey A K. Knowledge about heart attack and hypertension among individuals attending a cardiac camp in Pokhara city. Kathmandu University Medical Journal. 2012; 5(18): 273-278.

19. Kilic M, Uzuncakmak T, Ede $H$. The effect of knowledge about hypertension on the control of high blood pressure. International Journal of the Cardiovascular Academy. 2016; 2(1): 27-32.

20. Kumar C, Sagar V, Kumar M, Kiran A K. Awareness about hypertension and its modifiable risk factors among adult population in a rural area of Ranchi district of Jharkhand, India. International Journal of Community Medicine and Public Health. 2016; 3(5): 1069-1073. 